\title{
PENGEMBANGAN INSTRUMEN PENILAIAN MENDENGARKAN SANDIWARA BAHASA JAWA SMP KELAS IX BERBASIS KULTURAL DI KOTA SEMARANG
}

\author{
Dian Prastya $^{1}$, Esti Sudi Utami ${ }^{2}$, Ucik Fuadhiyah $^{3}$
}

1,2,3Jurusan Bahasa dan Sastra Jawa, Fakultas Bahasa dan Seni, Universitas Negeri Semarang Corresponding Author: dianprastya@gmail.com ${ }^{1}$

\begin{abstract}
Abstrak
Penelitian ini didasari pada kenyataan bahwa penilaian mendengarkan sandiwara di sekolah belum sesuai dengan keterampilan mendengarkan wacana sastra. Oleh karena itu, penelitian ini mengembangkan instrumen penilaian mendengarkan sandiwara berbasis kultural. Penelitian ini menggunakan desain peneitian Research and Development. Data penelitian diperoleh dari wawancara dan angket uji validasi. Instrumen yang dihasilkan sesuai dengan kebutuhan guru, yaitu instrumen penialaian sandiwara berbasis kultural yang berisikan rekamana sandiwara Pangeran Mangkubumi (Pandanaran II) dan sembilan bentuk soal mendengarkan wacana sastra.Hasil uji ahli menyatakan bahwa instrumen dan rekaman sandiwara valid dengan revisi.

Kata Kunci: mendengarkan sandiwara, instrumen penilaian
\end{abstract}

\section{Abstract}

This study is based on the fact that the listening rating achievments of the school play have not in accordance with literary discourse listening test. Usually, the teacher only gives brief description of the play. Therefore, the aim of this study is develop cultural based of listening instrument in thetrical subject. This reseach uses resesarch and development design. Reseach data were obtained from interviews and valid test questionnaires. The instrument produced according to the eeds of the teacher, the instrument of culturalbased theatrical play which contains the recording of the plays of Prince Mangkubumi (Pandanaran II) and nine forms of listening to the literally discourse. Expert states that the instruments and recording of plays are valid with revisions.

Keywords: listening, drama, assessment instruments 
Dian Prastya, dkk/ Piwulang 7 (2) (2019)

\section{PENDAHULUAN}

Setiap kegiatan belajar pasti memiliki tujuan pembelajaran yang ingin dicapai. Untuk mengetahui ketercapaian tujuan pembelajaran dapat diukur dengan kegiatan evaluasi. Evaluasi pembelajaran dapati dilakukan dalam kurun waktu tertentu. Evaluasi pembelajaran dilakukan untuk mengetahui kemampuan siswa dalam memahami suatu materi pembelajaran berdasarkan kompetensi dan indikator yang telah ditentukan.

Kegiatan penilaian penting untuk dilaksanakan dalam setiap akhir pembelajaran. Evaluasi yang dilakukan juga harus mampu mengukur setiap materi yang sudah dipelajari sehingga evaluasi tersebut dapat dikatakan sebagai evaluasi yang baik. Setiap penilaian tentu harus dilakukan seobjektif mungkin.

Dalam penilaian mendengarkan evaluasi harus disesuaikan dengan tujuan pembelajaran mendengarkan sendiri. Tujuan pembelajaran mendengarkan yaitu pengembangan kemampuan mendengarkan, menanggapi, dan memahami berbagai wacana lisan. Untuk mengetahui hasil evaluasi, terdapat beberapa teknik dan alat penilaian yang dapat digunakan guru. Penggunaan berbagai teknik dan alat penilaian harus disesuaikan dengan tujuan penilaian, waktu yang tersedia, tugas yang diberikan kepada siswa, dan materi pelajaran yang telah disampaikan. Misalnya, untuk penilaian mendengarkan tentu perlu disusun instrumen dengan mengindahkan berbagai kaidah dan persyaratan penilaian mendengarkan yang baik. Persiapan yang perlu dilakukan oleh guru dalam melakukan penilaian mendengarkan diantaranya berupa materi rekaman. Diperlukan pula jenis soal yang sesuai dengan tes kemampuan mendengarkan.

Berdasarakan hasil pengamatan di lapangan, kegiatan penilaian sandiwara bahasa
Jawa di sekolah belum sesuai kompetensi dasar dan indikator yang telah ditentukan. Indikator yang ditetapkan dalam KD menelaah naskah sandiwara contohnya mendengarkan wacana teks dialog sandiwara bahasa Jawa. Indikator ini rupanya belum diukur secara tepat karena penilaian yang dilakukan tidak dengan mengukur kemampuan mendengarkan. Kegiatan penilaian mendengarkan sering dilakukan dengan tes kemampuan membaca.

Penilaian mendengarkan sandiwara bahasa Jawa sendiri hendaknya disesuaikan dengan tingkat kemampuan berbahasa Jawa siswa. Diperlukan pemilihan struktur kalimat, ejaan, serta diksi yang tepat supaya siswa dapat memahami isi sandiwara bahasa Jawa dengan mudah. Hal ini sesuai dengan tujuan dasar pembelajaran bahasa Jawa supaya siswa mampu berkomunikasi menggunakan bahasa Jawa dengan baik dan benar.

Pemilihan sandiwara dalam penelitian ini adalah berbasis kultural. Sandiwara yang berbasis kultural ini dipilih dengan tujuan meningkatkan pengetahuan siswa terhadap nilai-nilai kebudayaan Jawa di sekitar tempat tinggal para siswa. Tentu saja dialek yang digunakan disesuaikan dengan dialek setempat sehingga siswa mampu memahami isi sandiwara dengan mudah. Hal yang bisa dilakukan guru pertama dengan memperdengarkan cerita sandiwara, kemudian siswa akan dituntun untuk mengeksplorasi isi sandiwara. Sandiwara tersebut digali nilai-nilai kebudayan Jawa yang sesuai dengan kehidupan seharihari.

Oleh karena itu, penelitian ini mengembangkan instrumen penilaian mendengarkan sandiwara berbasis kultural untuk siswa SMP kelas IX di Kota Semarang yang lebih variatif.

Instrumen penilaian digunakan untuk mengukur dan menilai proses serta hasil pembelajaran yang telah dilakukan terhadap siswa. Menurut Melawi (2000), instrumen penilaian mendengarkan dapat 
berupa; a) menirukan kembali, b) melaksankan petunjuk atau perintah, c) menjawab pertanyaan apa, siapa, dimana, mengapa, berapa, dan bagaimana, d) menerka nama benda, binatang, nama tempat, dan lain lain, e) menanyakan berbagai hal berdasarkan tema / topik, f) menyampaikan atau menerima pesan, g) mengurutkan gambar, h) menentukan satu dari empat gambar (A, B, C, dan D) berdasarkan yang didengarkan), i) mengisi kalimat rumpang, j) Fill-in table atau mengisi tabel berdasarkan apa yang didengar.

Instrumen penilaian mendengarkan sandiwara akan diintegrasikan dengan penilaian kesastraan yang meliputi; tes kesastraan tingkat informasi (menanyakan hal kesastraan), tes kesastraan tingkat konsep (menayakan unsur pembangun karya sastra), tes kesastraan tingkat perspektif (menanyakan pandangan), tes kesastraan tingkat apresiasi (menanyakan hubungan karya sastra dengan kebahasaan, analisis, dan menilai) serta penilaian dalam kurikukum 2013 yaitu; penilaian sikap, penilaian pengetahuan, dan penilaian keterampilan.

Sandiwara yang diajarkan di SMP tentang unsur-unsur pembangun sandiwara, berupa; 1) tema atau ide dhasar crita; 2) plot/alur atau dalaning cerita; 3) tokoh dan perwatakan atau paraga lan watake; 4) latar/setting atau papan panggonan kadadeyan; 5) amanat atau pesen moral. Pengintegrasian pembelajaran kebudayaan ke dalam bahan ajar sandiwara melalui tema-tema yang dipilih, seperti pendidikan, adat istiadat, dan kesenian masayarakat Jawa khususnya daerah Semarang.

\section{METODE PENELITIAN}

Penelitian ini menggunakan desain penelitian pengembangan atau Research and
Development (R\&D). Subjek dalam penelitian ini adalah guru dan para ahli.

Teknik pengumpulan data dalam peneliian ini meliputi; teknik wawancara, dan angket penilaian ahli. Wawancara dilakukan kepada guru, guna mendapatkan data kebutuhan guru terhadap instrumen penilaian mendengarkan sandiwara bahasa Jawa berbasis kultural, angket uji ahli digunakan untuk mengetahui kelayakan instrumen penilaian.

Teknik analisis data menggunakan teknik analisis interaktif. Hasil dari wawancara dan angket uji ahli kemudian dianalisis untuk kemudian dideskripsikan sebagai hasil.

\section{HASIL DAN PEMBAHASAN}

Penelitian ini mengembangkan instrumen penilaian mendengarkan sandiwara bahasa jawa SMP kelas IX berbasis kultural di kota Semarang. Deskripsi dari hasil penelitian ini, meliputi: kebutuhan guru terhadap instrumen penilaian mendengarkan sandiwara bahasa Jawa berbasis kultural, pengembangan instrumen penilaian mendengarkan berbasis kultural, dan uji ahli instrumen penilaian mendengarkan sandiwara berbasi kultural.

\section{Kebutuhan guru}

Wawancara dilakukan dengan tiga guru bahasa Jawa dari sekolah yang berbeda, yaitu: SMP Negeri 2, SMP Negeri 5, dan SMP Negeri 9 Semarang.

Hasil dari analisis wawancara yang telah dilakukan menunjukkan bahwa guru menggunakan instrumen penilaian yang relatif sama untuk materi sandiwara, yaitu dengan memberikan pertanyaan tentang unsur instrinsik sandiwara dengan bentuk soal pertanyaan $5 \mathrm{~W}+1 \mathrm{H}$. Bentuk soal yang diberikan hanya sebatas uraian singkat. Selain itu, guru terkadang memberikan tugas siswa dengan membuat pertanyaan sendiri kemudian ditukarkan dengan teman sebangku untuk dijawab. 
Bentuk penilaian akhir yang diberikan masingmasing sekolah juga relatif sama, dengan memberikan soal uraian terbatas, menganalisis unsur intrinsik, dan menceritakan kembali. Berbeda dengan guru bahasa Jawa SMP Negeri 2 Semarang yang melakukan penilaian akhir dengan cara pementasan sandiwara di depan kelas. Aspek penilaian yang dilakukan meliputi, pemahaman siswa terhadap naskah, mimik wajah, dan

penggunaan bahasa Jawa krama atau ngoko yang sesuai unggah ungguh.

Hasil dari wawancara dengan ketiga guru menyebutkan bahwa, guru hanya melaksanakan penilaian dengan memberikan soal uraian singkat. Penilaian aspek mendengarkan belum dilaksanakan secara maksimal, sehingga instrumen penilaian mendengarkan dan variasi soal sangat diperlukan oleh guru untuk meningkatkan serta mengukur kemampuan mendengarkan siswa. Pemilihan tema sandiwara yang memuat nilai-nilai budaya kota Semarang. Hal ini bertujuan agar siswa mengetahui cerita tentang pemimpin di kotanya.

Ketiga guru setuju apabila dikembangkan instrumen penilaian mendengarkan sandiwara berbasis kultural untuk siswa, dengan harapan instrumen penilaian dapat digunakan sebagai acuan apakah siswa sudah memiliki keterampilan mendengarkan yang baik. Penggunaan bahasa Jawa krama bertujuan agar siswa belajar mengenai unggah-ungguh, serta menambah pengetahuan kosa kata bahasa Jawa krama. Hal ini sesuai sengan tujuan pembelajaran bahasa Jawa, yaitu siswa mampu berkomunikasi menggunakan bahasa Jawa baik krama maupun ngoko dengan baik dan benar.

\section{Pengembangan instrumen penilaian mendengarkan}

Setelah dilakukan analisis tentang kebutuhan guru, langkah selanjutnya yaitu menyusun draf instrumen penilaian mendengarkan sandiwara berbasis kultural. Dari hasil analisis diperoleh deskripsi mengenai instrumen yang dibutuhkan berupa rekaman sandiwara yang memuat cerita tentang Semarang dan variasi bentuk soal.

Tabel 1. Kisi-kisi Soal KD Menelaah Naskah Sandiwara

\begin{tabular}{|c|c|c|c|}
\hline No & Tes Kesastraan & $\begin{array}{c}\text { Bentuk } \\
\text { Soal }\end{array}$ & $\begin{array}{c}\text { Jumlah } \\
\text { Pertanya } \\
\text { an }\end{array}$ \\
\hline 1. & $\begin{array}{l}\text { Informasi, } \\
\text { konsep, } \\
\text { perspektif }\end{array}$ & $\begin{array}{l}\text { Pilihan } \\
\text { Ganda }\end{array}$ & 10 \\
\hline 2. & $\begin{array}{l}\text { Informasi, } \\
\text { konsep }\end{array}$ & $\begin{array}{l}\text { Benar } \\
\text { Salah }\end{array}$ & 5 \\
\hline 3. & Informasi & $\begin{array}{l}\text { Menjodoh } \\
\text { kan }\end{array}$ & 5 \\
\hline 4. & Informasi & $\begin{array}{l}\text { Mengisi } \\
\text { Tabel }\end{array}$ & 5 \\
\hline 5. & Perspektif & $\begin{array}{l}\text { Uraian } \\
\text { Terbatas }\end{array}$ & 5 \\
\hline 6. & $\begin{array}{l}\text { Perspektif, } \\
\text { kesastraan }\end{array}$ & $\begin{array}{l}\text { Melengka } \\
\text { pi Wacana } \\
\text { Rumpang }\end{array}$ & 6 \\
\hline 7. & Informasi & $\begin{array}{c}\text { Mendeskri } \\
\text { psikan }\end{array}$ & 4 \\
\hline 8. & Konsep & $\begin{array}{c}\text { Tokoh } \\
\text { Mendeskri } \\
\text { psikan } \\
\text { Gambar }\end{array}$ & 4 \\
\hline 9. & Apresiasi & $\begin{array}{c}\text { Mencerita } \\
\text { kan Kembali }\end{array}$ & $\begin{array}{l}\text { Minimal } \\
\text { lima } \\
\text { baris. }\end{array}$ \\
\hline
\end{tabular}


Dian Prastya, dkk/ Piwulang 7 (2) (2019)

Naskah Sandiwara

Pemilihan tema sandiwara disesuaikan dengan cerita yang ada di Kota Semarang. Cerita tentang Pangeran Mangkubumi atau Pandaran II dipilih sebagai naskah rekaman sandiwara. Hal ini sebagai pengetahuan untuk siswa terhadap tokoh pemimpin kotanya di masa lampau dan sebagai pembelajaran tentang tanggung jawab seorang pemimpin.Penggunaan bahasa Jawa yang baik dan benar juga diterapkan sebagai contoh kepada siswa dalam mempelajari unggah-ungguh.

\section{Rekaman Sandiwara}

Hasil rekaman sandiwara berupa kepingan CD mp3 dan soft file mp3 menggunakan menggunakan aplikasi Adobe Audition 3.0. isi rekaman sandiwara dilengkapi dengan backsound dan efek suara untuk memberikan kesan drama dalam rekaman sandiwara. Pengambilan suara dilakukan oleh 4 orang yang berperan sebagai $\mathrm{Ki}$ Ageng Pandanaran, Pangeran Mangkubumi, Sunan Kalijaga, Abdi Suraji, dan prolog.

\section{Variasi Bentuk Soal}

Variasi bentuk soal yang didapatkan dalam pengembangan instrumen penilaian mendengarkan sandiwara berbasis kultural, meliputi: (a) pilihan ganda, (b) benar salah, (c) menjodohkan, (d) mengisi tabel, (e) uraian terbatas, (f) melengkapi wacana rumpang, (g) mendeskripsikan tokoh, (h) mendeskripsikan gambar, dan (i) menceritakan kembali.

\section{Hasil Uji Ahli}

Uji validasi bertujuan mengukur kelayakan instrumen penilaian mendengarkan sandiwara berbasis kultural. Uji validasi dilakukan oleh ahli materi dan ahli media melalui pengisian angket penilaian ahli.

Uji validasi dari segi kelayakan materi dan media yang terdapat dalam instrumen penilaian mendengarkan sandiwara berbasis kultural dilakukan oleh ahi. Indikator untuk penilaian materi meliputi kelayakan rekaman sandiwara dan kesesuaian soal.

Pada indikator kelayakan rekaman sandiwara bagian isi, terdapat beberapa penilaian yang harus diperhatikan. Penekanan pada peristiwa dan alur cerita sebagai upaya pemahaman isi cerita serta kronologi yang belum terlihat jelas. Hal ini disebabkan karena sandiwara terlalu singkat, sehingga tidak semua peristiwa dapat disajikan secara utuh.

Segi bahasa yang digunakan dalam rekaman sandiwara sesuai untuk siswa SMP yaitu penggunaan bahasa Jawa krama, namun terdapat beberapa diksi yang kurang sesuai atau tidak lazim digunakan oleh masyarakat awam. Penekanan dialek Semarang perlu dipertegas supaya instrumen penilaian dapat dikategorikan berbasis kultural.

Kelayakan rekaman sandiwara pada bagian penyajian mendapatkan nilai yang buruk. Hal ini dikarenakan, rekaman sandiwara terdengar kurang jelas, pelafalan yang kurang tegas antara da dengan dha, suara antar tokoh kurang jelas perbedaannya. Rekaman sandiwara terdengar jelas dikarenakan terlalu kencang suara backsound dan efek suara, sehingga perlu diperbaiki dalam penyusunan backsound dan efek suara pada saat dialog terjadi. Segi pelafalan dan suara tokoh perlu diperbaiki, tokoh kurang begitu fasih 
Dian Prastya, dkk/ Piwulang 7 (2) (2019)

berbahasa Jawa sehingga dialek Semarangan dan pelafalan diksi bahasa Jawa tidak terdengar jelas. Kelayakan instrumen penilaian mendengarkan sesuai dengan dengan empat bentu tes kesastraan, yaitu tes kesastraan tingkat infirmasi, tes kesastraan tingkat konsep, tes kesastraan tingkat perspektif, dan tes kesastraan tingkat apresiasi.

Hasil uji validasi mendapatkan sembilan bentuk soal yang berbeda, yaitu pilihan ganda, benar salah, menjodohkan, mengisi tabel, uraian terbatas, melengkapi wacana rumpang, mendeskripsikan tokoh, mendeskripsikan gambar, dan menceritakan kembali. Kesembilan bentuk soal sudah lolos uji validasi dan siap digunakan. Dari hasil uji validitas yang dilakukan oleh kedua dosen jurusan bahasa jawa Unnes, menyebutkan bahwa instrumen siap digunakan dengan catatan media rekaman sandiwara harus diperbaiki.

Revisi yang dilakukan hanya sebatas penekanan suara para tokoh dan dan pengurangan volume backsound agar sandiwara dapat dinikmati dengan jelas di ruang kelas.

\section{SIMPULAN}

Berdasarkan hasil penelitian dan pembahasan, dapat disimpulkan bahwa guru membutuhkan intrumen penilaian mendengarkan sandiwara berbasis kultural, untuk meningkatkan keterampilan mendengarkan bahasa Jawa siswa. Berdasarkan uji validasi dinyatakan valid dengan revisi. Adapun revisi yang dilakukan, meliputi: penekanan suara antar tokoh dan volume backsound yang perlu dikurangi.
Saran yang dapat disampaikan, yaitu supaya guru menggunakan instrumen dan rekaman sandiwara sebagai media pembelajaran sandiwara kepada siswa, agar siswa lebih tertarik mengikuti pembelajaran sandiwara. Oleh karena itu, perlu dilakukan penelitian lanjutan untuk menyempurnakan dan menguji keefektifan instrumen.

\section{DAFTAR PUSTAKA}

Abidin, Yunus. 2012. Pembelajaran Bahasa Berbasis Pendidikan Karakter. Bandung: Refika Aditama.

Anggraeni, Ristiya Dwi. 2011. Variasi Soal Evaluasi Aspek Mendengarkan dalam RPP Bahasa Jawa Kelas VII SMP Negeri se-Kecamatan Pati. Skripsi. Semarang: Universitas Negeri Semarang.

Arikunto, S. 2010. Prosedur Penelitian Suatu Pendekatan Praktik Ed revisi. Jakarta : Rineka Cipta.

Budianta, Melainie, dkk. 2002. Membaca Sastra. Magelang: Indonesiatera.

Campbell, Robyn. 2011. The Power of Listening Ear: English Journal.. Illionis: National Council of Teachers of English. Vol. 100,NO. 5:66-67.

Damaianti, Vismaia Sabariah. 2007. "Evaluasi dalam Pembelajaran". Makalah.

Daryanto. 2008. Evaluasi Pendidikan. Jakarta: Rineka Cipta.

Djiwandono, Soenardi. 2008. Tes Bahasa: Pegangan Bagi Pengajar Bahasa. Jakarta: Indeks.

Ibrahim. Nana Syaodih. 2003. Perencanaan Pengajaran. Jakarta: Rineka Cipta.

Maulina, Oktalifa Hanna. Ririn. 2015. Penilaian Proyek sebagai Implementasi Authentic Assessment untuk Meningkatkan Motivasi Pembelajaran Drama di Sekolah. Seminar Nasioal Pendidikan Bahasa Indonesia.

Nurgiyantoro, Burhan. 2007. Teori Pengkajian Fiksi. Yogyakarta: Gajah Mada Univeristy Press.

Nurgiyantoro, Burhan. 2001. Penilaian dalam Pengajaran Bahasa dan Sastra. Yogyakarta: BPFE- YOGYAKARTA.

Nurgiyantoro, Burhan. 2009. Penilaian dalam Pengajaran Bahasa dan Sastra. Yogyakarta: BPFE.

Sudijono, Anas. 2011. Pengantar Evaluasi Pendidikan. Depok: Rajawali Press

Sugiyono, 2008. Metode Penelitian Kuantitatif, Kualitatif dan $R \& D$. Jakarta

Alfhabeta. 